\title{
PROPOSTA DE ÍNDICE DE QUALIDADE DE ÁGUA PARA A LAGOA DO APODI, RN, BRASIL
}

\author{
J. L. O. PINTO FILHO', E. G. SANTOS ${ }^{2}$ e M. J. J. B SOUZA ${ }^{3}$ \\ 1,2,3 Universidade Estadual do Rio Grande do Norte (UERN) \\ E-mail: jorgefilho@uern.br ${ }^{1}$,edna-gui@bol.com.br ${ }^{2}$ e jamillesouza86@hotmail.com ${ }^{3}$
}

Artigo submetido em outubro/2011 e aceito em abril/2012

\section{RESUMO}

O presente trabalho teve por objetivo elaborar um Índice de Qualidade da Água (IQA) para a Lagoa do Apodi- RN. Os pontos encontram-se sob diferentes influências antrópicas e foram monitorados no período estiagem de 2009, nos meses de julho, setembro e novembro; e no período chuvoso de 2010, nos meses de janeiro, março e maio, em quatro estações distribuídas ao longo do trecho urbanizado da Lagoa do Apodi-RN, sendo analisados os seguintes parâmetros: coliformes termotolerantes, $\mathrm{pH}$, Demanda Bioquímica de Oxigênio, Nitrogênio Total, Fosfato Total, Temperatura, Turbidez,
Resíduo Total e Oxigênio Dissolvido; os quais serviram de base para o desenvolvimento do IQA do referido ambiente aquático. Observou-se que o pior IQA da água foi registrado na estação seca, e o melhor no final da estação chuvosa. As estações 3 e 4 foram as que apresentaram o pior IQA, devido ao altos índices de coliformes termotolerantes e baixo valor de oxigênio dissolvido. Esta menor qualidade de água pode ser atribuída à maior concentração demográfica da região e ausência de sistema de esgotamento sanitário.

PALAVRAS-CHAVE: Qualidade de água. Monitoramento de água. Recursos hídricos. Poluição hídrica.

\section{WATER QUALITY INDEX PROPOSED OF APODI LAGOON, RN, BRAZIL}

\section{ABSTRACT}

This study was carried out to assess water quality index (WQI) of Apodi-RN Lagoon. Items are under different anthropogenic influences and were monitored during the 2009 drought in the months of July, September and November and the rainy season of 2010, in January, March and May, at four stations distributed throughout the urbanized portion of the Lagoon Apodi-RN, and analyzed the following parameters: fecal coliform, $\mathrm{pH}$, biochemical oxygen demand, Total Nitrogen, Total Phosphorus (TP), temperature, turbidity, total residue and Dissolved Oxygen (DO), which served the basis for the development of the WQI of this aquatic environment. It was observed that the worst WQI water was recorded in the dry season, and better at the end of the rainy season. Stations 3 and 4 were the ones with the worst WQI due to high levels of fecal coliform and low dissolved oxygen value. This lower water quality can be attributed to the higher population concentration in the region and no sewage system.

KEY-WORDS: Water quality. Water monitoring. Water resources. Water pollution. 


\section{PROPOSTA DE ÍNDICE DE QUALIDADE DE ÁGUA PARA A LAGOA DO APODI, RN, BRASIL}

\section{INTRODUÇÃO}

A água é o recurso natural mais abundante no planeta, compondo a paisagem e o meio ambiente e, sendo necessário para quase todas as atividades humanas (PEREIRA, 2004). A utilização dos recursos hídricos varia conforme sua qualidade, com isso podendo ser para os seguintes usos: consumo humano, atividades agrícolas e pecuárias, geração de energia elétrica, transporte hidroviário, uso industrial, pesca e aqüicultura e turismo lazer (LIMA et al., 2008).

Com esses variados usos os recursos hídricos tornam-se vulneráveis ao processo de poluição através da adição de substâncias ou de formas de energia que, diretamente ou indiretamente, alteram a natureza do corpo d'água de uma maneira que prejudiquem os legítimos usos que dele são feitos (SPERLING, 1996),

Sendo assim, Andrade et al. (2010) aponta que a poluição da água é intensificada no período de estiagem, devido principalmente a diminuição do volume de armazenamento de água no corpo receptor, fazendo com que, aumente a concentração dos poluentes no referido ambiente aquático. Em pesquisa sobre a qualidade da água do Rio Poty, em Teresina, PI Damasceno et al. (2010) constataram que os maiores índices de poluentes ocorreram no período seco devido proporcionar aumento na evaporação das águas e redução da capacidade de diluição dos efluentes lançados.

Cabe destacar, que a poluição das águas não se acentua apenas na variável temporal, mas também ao longo do espaço, com isso Silva et al. (2008) ao afirmam que o uso e ocupação do solo interferem na qualidade da água. Para Poleto et al. (2004) o uso inadequado dos solos, o desmatamento sem manejo e o uso indiscriminado de fertilizantes, corretivos e agrotóxicos provoca inúmeros problemas ambientais, principalmente relacionado a qualidade e quantidade de água drenada pela bacia hidrográfica.

Ainda sobre as fontes de poluição hídrica Pereira (2004) destaca as relacionadas aos esgotos domésticos, despejos industriais, escoamento da chuva das áreas urbanas, das águas de retorno de irrigação e atividade de mineração.

Com isso, os efeitos da poluição das águas estão ligados na diminuição do oxigênio dissolvido, salinização das águas de superfície e subterrânea, aumento da temperatura e presença de substâncias orgânicas tóxicas (SPIRO e STIGLIANI, 2009).

Diante dessa situação, faz necessários estudos sobre avaliação da qualidade da água para estimular ações de controle ambiental. Nesse sentido, o debate sobre a questão da qualidade das águas não ocorre nos maiores aglomerados urbanos. No Rio Grande do Norte, existe uma enorme lacuna sobre estudos científicos a questão ambiental. Assim, este trabalho torna-se relevante na medida em que se propõe conhecer os impactos socioambientais da ação antrópica sobre os recursos hídricos da Lagoa do Apodi-RN.

O reservatório da lagoa do Apodi conforme Lemos et al. se situa no semiárido nordestino, inserido na bacia potiguar, que ocupa parte do Rio Grande do Norte e, tem uma grande importância econômica para o bairro Malvinas, uma vez que $29,3 \%$ da população dessa área desenvolvem a pesca nesse ambiente aquático (PINTO FILHO e OLIVEIRA, 2009). 
Entretanto, apesar da enorme importância ambiental, a referida lagoa, a exemplo de tantos outros ambientes aquáticos se encontra inserida na problemática ambiental, já que é submetida a agressões constantes, principalmente, de ordem urbana e agrícola.

Portanto, o presente trabalho teve por objetivo elaborar um Índice de Qualidade da Água (IQA) para a Lagoa do Apodi- RN.

\section{MATERIAL E MÉTODOS}

\section{Pontos de coleta}

Os pontos de coletas consistem de uma amostragem ao longo da área urbana da Lagoa do Apodi-RN, onde com o auxílio do GPS Garmin eTrex, quatro pontos de coleta foram devidamente georreferenciados (Tabela 1 ), sendo estes: $\mathrm{P}_{01}$-Balneário, $\mathrm{P}_{02}$-Lagoa do Canto, $\mathrm{P}_{03}$-Calçadão e $\mathrm{P}_{04}{ }^{-}$ Esgoto.

Tabela 1 - Coordenadas georreferenciadas dos 4 pontos de coleta na Lagoa do Apodi-RN.

\begin{tabular}{ccccc}
\hline Pontos & $\mathbf{P}_{01}$ & $\mathbf{P}_{02}$ & $\mathbf{P}_{03}$ & $\mathbf{P}_{04}$ \\
\hline Latitude & $5^{\circ} 40^{\prime} 7.99^{\prime \prime} \mathrm{S}$ & $5^{\circ} 39^{\prime} 57.12^{\prime \prime} \mathrm{S}$ & $5^{\circ} 40^{\prime} 10.57^{\prime \prime} \mathrm{S}$ & $5^{\circ} 40^{\prime} 14.67^{\prime \prime} \mathrm{S}$ \\
Longitude & $37^{\circ} 48^{\prime} 20.64^{\prime \prime O}$ & $37^{\circ} 48^{\prime} 13.39^{\prime \prime} \mathrm{O}$ & $37^{\circ} 48^{\prime} 3.65^{\prime \prime O}$ & $37^{\circ} 47^{\prime} 44.18^{\prime \prime O}$ \\
Elevação $(\mathrm{m})$ & $45 \mathrm{~m}$ & $60 \mathrm{~m}$ & $49 \mathrm{~m}$ & $44 \mathrm{~m}$ \\
\hline
\end{tabular}

Os locais de amostragem da qualidade da água foram escolhidos mediante fatores que potencialmente poderiam influenciar, diretamente ou indiretamente, de forma significativa, a qualidade do corpo d'água, incluindo descargas, tanto pontuais quanto difusas, e, conforme estudo de Lemos et al. (2009) sobre a sazonalidade e variabilidade espacial da qualidade da água na Lagoa do Apodi-RN.

As amostras foram coletadas em triplicata na área urbana da Lagoa do Apodi-RN, onde os parâmetros $\mathrm{pH}$, Oxigênio Dissolvido e Temperatura foram analisados no campo com o auxílio de um equipamento multi-parâmetro, enquanto os parâmetros Demanda Bioquímica de Oxigênio (DBO), Sólidos Totais, Nitrogênio Total, Fosfato Total, Turbidez e coliformes termotolerantes foram analisados no Laboratório do Departamento de Química da Universidade do Estado do Rio Grande do Norte - UERN.

Para cada tipo de análise, adotou-se uma metodologia específica de coleta e preservação de amostras, baseada no roteiro do APHA (1995), para garantir o acondicionamento e o armazenamento adequados, além do tempo máximo permitido entre a coleta e a análise, de maneira a não comprometer a integridade da amostra e, conseqüentemente, os resultados das análises. Relativo aos procedimentos analíticos, todas as análises foram realizadas seguindo os padrões preconizados em APHA et al. (1992).

As amostragens foram sazonais de forma a descrever o comportamento dos corpos d'água ao longo das estações climáticas, totalizando seis amostras do período de estiagem de 2009, compreendendo os meses de julho, setembro e novembro; até o período chuvoso de 2010, correspondente aos meses de janeiro, março e maio.

Aos dados de qualidade da água foi aplicado o Índice de Qualidade de Água (IQA) por considerar uma metodologia integradora de diversas informações num único resultado numérico (ALMEIDA e SCHRWARZBOLD, 2003). Com isso, o IQA proposto pela CETESB (2007), é calculado 
com base nos parâmetros: coliformes termotolerantes, $\mathrm{pH}$, Demanda Bioquímica de Oxigênio, Nitrogênio Total, Fosfato Total, Temperatura, Turbidez, Resíduo Total e Oxigênio Dissolvido. Cada parâmetro foi adotado um peso pelo CETESB conforme sua importância no cálculo do IQA apresentados na Tabela 2.

Tabela 2 - Peso dos parâmetros representativos para o cálculo do IQA.

\begin{tabular}{ccc}
\hline PARÂMETRO & UNIDADE & PESO (W) \\
\hline Coliformes Termotolerantes (CTer) & $\mathrm{NMP} / 100 \mathrm{MI}$ & 0,15 \\
Ph & - & 0,12 \\
Demanda Bioquímica de Oxigênio (DBO) & $\mathrm{mg} \mathrm{O}_{2} / \mathrm{L}$ & 0,10 \\
Nitrogênio Total (NT) & $\mathrm{mg} \mathrm{N} / \mathrm{L}$ & 0,10 \\
Fosfato Total (PT) & $\mathrm{mg} \mathrm{P} / \mathrm{L}$ & 0,10 \\
Temperatura (Ta) & ${ }^{\circ} \mathrm{C}$ & 0,10 \\
Turbidez (Tur) & $\mathrm{UNT}$ & 0,08 \\
Resíduo Total (ST) & $\mathrm{Mg} / \mathrm{L}$ & 0,08 \\
Oxigênio Dissolvido (OD) & \% saturação & 0,17 \\
\hline
\end{tabular}

Fonte: Adaptado CETESB (2007).

O IQA é calculado pelo produtório ponderado das qualidades de água correspondentes aos parâmetros conforme a fórmula:

9

Onde:

$$
I Q A=\prod_{\mathrm{I}=1} \mathrm{q}_{\mathrm{i}}{ }^{\mathrm{wi}}
$$

IQA= Índice de Qualidade da Água, (varia de 0 a 100); qi = qualidade do i-ésimo parâmetro, (entre 0 e 100); obtido por meio da curva média especifica de qualidade em função de sua concentração ou medida; wi = o peso atribuído ao i-ésimo parâmetro, em função da sua importância na qualidade, entre 0 e 1. A faixa de classificação do IQA varia de zero a cem a qual qualifica a água desde péssima a excelente passando pelas faixas ruim, aceitável e boa (Tabela 3).

Tabela 3 - Faixas de qualidade do IQA.

\begin{tabular}{cc}
\hline Nível de Qualidade & Faixa \\
\hline Excelente & $90<\mathrm{IQA}<100$ \\
Bom & $70<\mathrm{IQA}<90$ \\
Médio & $50<\mathrm{IQA}<70$ \\
Ruim & $25<\mathrm{IQA}<50$ \\
Muito Ruim & $0<\mathrm{IQA}<25$ \\
\hline
\end{tabular}

Fonte: Adaptado IGAM (2003).

\section{RESULTADOS E DISCUSSÃO}

A Lagoa do Apodi-RN, no geral, apresenta nível médio de qualidade de água para consumo humano com base no IQA, em relação aos parâmetros analisados neste trabalho, porém em alguns momentos é possível encontrar águas em nível ruim. De acordo com a tabela 4, 
observa-se que houve variabilidade temporal e espacial do IQA da Lagoa do Apodi-RN, com maior predomínio da variável temporal.

Tabela 4 - Valores do IQA para as águas do trecho urbanizado da Lagoa do Apodi-RN, durante o período de monitoramento.

\begin{tabular}{lcccc}
\hline DATA DE AMONSTRAGEM & \multicolumn{4}{c}{ IQA } \\
\cline { 2 - 5 } & Balneário & Lagoa do Canto & Calçadão & Esgoto \\
\hline 10/07/2009 & 58,88235082 & 41,38998723 & 37,9654713 & 50,31240651 \\
$03 / 09 / 2009$ & 50,03918448 & 40,62478594 & 37,3757939 & 50,29909828 \\
$07 / 11 / 2009$ & 49,45050505 & 38,85858585 & 35,9393939 & 47,02292929 \\
$17 / 01 / 2010$ & 53,03857444 & 40,98300303 & 37,7484848 & 50,99492864 \\
$22 / 03 / 2010$ & 57,78933344 & 43,39485754 & 42,3044455 & 52,45964055 \\
$25 / 05 / 2010$ & 63,88235082 & 50,94875045 & 50,5405837 & 57,40596843 \\
\hline
\end{tabular}

Observa-se na Tabela 04 tendência de diminuição do IQA da Lagoa do Apodi-RN no período de estiagem, devido o aumento do escoamento superficial permitir diluir os contaminantes presentes nesse corpo receptor. Portanto, o efeito diluição dos poluentes foram maior que o transportador do deflúvio. Cabe ressaltar que a diminuição do IQA intensifica no período de seca, principalmente no mês de novembro, época de menor índice pluviométrico do município de Apodi-RN conforme IDEMA (2009), sendo em torno de $30 \mathrm{~mm}$.

Andrade et al. (2005) encontraram resultados semelhantes para o índice de qualidade de água, do Vale do rio Trussu, localizado no estado do Ceará, uma vez que observaram o pior IQA na estação seca. Ao estudarem a qualidade das águas do rio Bangpakong no leste da Tailândia Bordalo et al. (2001) identificou variação sazonal nos valores do IQA.

Verifica-se ao longo do tempo estudado, uma tendência decrescente na qualidade destas águas durante o período de estiagem, com recuperação significativa na época chuvosa, chegando ao nível médio do IQA da Lagoa do Apodi-RN no último mês do monitoramento. Tal situação pode ser explicada por Andrade et al. (2005) ao mencionarem que a diluição no período das chuvas causam uma variação nos valores de IQA.

Em estudos sobre o monitoramento das águas do Rio Mossoró/RN no perímetro urbano de Mossoró/RN Araújo et al. (2007) encontram uma variação temporal no IQA desse ambiente aquático, com aumento desse índice no período chuvoso, devido à sazonalidade climática alterar as concentrações dos contaminantes por intermédio da variação do volume do rio o período.

No que diz respeito a variabilidade espacial os piores IQA's encontram-se situados nas estações 2 e 3 (Tabela 4) devido à maior concentração demográfica da região e ausência de sistema de esgotamento sanitário nessas áreas. Sendo assim, pode-se inferir que a forma do uso e ocupação das margens da Lagoa do Apodi-RN têm gerados risco à qualidade da água desse reservatório.

Tal pensamento é corroborado por Silva et al. (2008) ao afirmar que o uso e ocupação do solo interferem na qualidade da água. Para Poleto et al. (2004) o uso inadequado dos solos, o desmatamento sem manejo e o uso indiscriminado de fertilizantes, corretivos e agrotóxicos provoca inúmeros problemas ambientais, principalmente relacionado a qualidade e quantidade de água drenada pela bacia hidrográfica. 
A correlação do IQA com o uso e ocupação do solo foi encontrada em estudos de Araújo et al. (2007) nas águas do Rio Mossoró/RN no área urbana de Mossoró/RN ao destacar a diminuição do IQA intensifica principalmente em locais com lançamento de esgotos domésticos e industriais sem o devido tratamento.

Cuelbas e Carvalho (2009) também encontraram variação espacial da qualidade da água na microbacia do Córrego Campestre no município de Lins-SP ao constatar diminuição do IQA nos pontos mais degradados onde a influência antrópica é mais acentuada.

Resultados semelhantes também foram encontrados por Pinto et al. (2009) ao investigaram a qualidade dos recursos hídricos superficiais, uma vez que encontraram os maiores IQA em áreas de predomínio de matas ciliares em comparado com os trechos de domínio de pastagem na ocupação do solo e com presença constante de queimadas.

Lopes et al. (2008) ao investigar a qualidade das águas do rio Acaraú, pelo emprego do IQA constataram que as águas enquadram-se em classes que vão de regular a boa. Para os mesmos autores não houve diferença significativa na avaliação temporal da qualidade das águas da bacia hidrográfica do Acaraú.

Ao comparar a variabilidade espacial com a temporal da Lagoa do Apodi-RN constata-se conforme a Tabela 4 que prevaleceu a espacial. Lopes et al. (2008) também encontraram maior variabilidade espacial do valor do IQA das águas da bacia hidrográfica do Acaraú em relação à variabilidade temporal.

Diante desses dados, cabe ressaltar que o IQA é um mecanismo que engloba diferentes variáveis que reflete a poluição das águas em um resultado numérico, entretanto, devido este método levarem em consideração parâmetros que apontam conseqüências imediatas, faz necessário um monitoramento da qualidade de ambientes aquáticos que contemple variáveis que causam efeitos prolongados e acumulativos, tais como metais pesados.

Somando-se a essas explicações aponta-se o raciocínio de que o IQA não atinge uma abordagem multidimensional por não considerar outros contaminantes potenciais importantes, como os defensivos agrícolas encontrados em seu estudo (CARVALHO et al., 2000).

Portanto, para uma análise mais detalhada da qualidade da água deve-se considerar uma série de outras variáveis importantes que não estão contempladas no IQA.

\section{CONSIDERAÇÕES FINAIS}

A Lagoa do Apodi atualmente vem sofrendo interferência pela ação antrópica, resultando na diminuição da qualidade físico-química e microbiológica da água desse ambiente aquático. Nesse sentido, adotou-se neste trabalho o Índice de Qualidade da Água-IQA como ferramenta de suporte á gestão dos recursos hídricos, uma vez que apresenta uma boa relação com o processo de enquadramento nas classes de uso da água.

Assim, a utilização do mecanismo IQA apontou que as águas da Lagoa do Apodi-RN enquadram-se em classes que vão de ruim à média.

No tocante a variabilidade temporal, percebe-se que a mesma exerce grande influência sobre as concentrações das variáveis consideradas, com tendência de diminuição do IQA da Lagoa do Apodi-RN no período de estiagem devido a diminuição do escoamento superficial 
provocando assim uma redução no volume de água desse corpo receptor para diluir os contaminantes.

No que diz respeito a variabilidade espacial os piores IQA's encontram-se situados nas estações 2 e 3 devido à influência antrópica ser mais acentuada, principalmente relacionada à maior concentração demográfica da região e ausência de sistema de esgotamento sanitário nessas áreas.

A variabilidade espacial do valor do IQA das águas da Lagoa do Apodi-RN foi superior a variabilidade temporal, tal fato deve-se a presença de matas ciliares em alguns locais, fazendo com que o elevasse o nível da qualidade da água em alguns trechos do ambiente estudado.

Para tanto, a efetivação do saneamento ambiental, recuperação da mata ciliar, projetos de educação ambiental e práticas de manejo sustentável fazem-se necessárias na Lagoa do Apodi para reduzir os problemas relacionados à poluição hídrica.

\section{REFERÊNCIAS}

ALMEIDA, M. A. B.; SCHWARZBOLD, A. Avaliação sazonal da qualidade das águas do Arroio da Cria Montenegro, RS com aplicação de um índice de qualidade de água (IQA). Revista Brasileira de Recursos Hídricos, v.8, n.01, p.81-97, 2003.

AMERICAN PUBLIC HEALTH ASSOCIATION - APHA, AMERICAN WATER WORKS ASSOCIATION AWWA, WATER ENVIROMENT FEDERATION - WEF. Standard Methods for the Examination of Water and Wastewater. 1992.

. Standard Methods for the Examination of Water and Wastewater. 1995.

ANDRADE, E. M. et al. Índice de qualidade de água: uma proposta para o vale do rio Trussu, Ceará. Revista Ciência Agronômica, v. 36, n. 02, p.135-142, 2005.

ANDRADE, E. M. et al. Mapa de vulnerabilidade da bacia do Acaraú, Ceará, à qualidade das águas de irrigação, pelo emprego do GIS. Revista Ciência Agronômica, v.37, n.03, p.279-286, 2006.

ARAújo, V. S. de; SANTOS, J. P. dos; ARAújo, A. L. C. Monitoramento das águas do Rio Mossoró/RN, no perímetro de abril/2005 a julho/2006. Revista Holos, Ano 23, 2007.

BORDALO, A. A.; NILSIMRANCHIT, W.; CHALERMWAT, K. Water quality and uses of the Bangpakong river (eastern Thailand). Water Research, v.35, n.15, p.3635-3642, 2001.

CARVALHO, A.R.; SCHLITTER, F.M.; TORNISIELO, V.L. Relações da atividade agropecuária com parâmetros físicos químicos da água. Química Nova, v.23, n.05, p.618-622, 2000.

COMPANHIA DE TECNOLOGIA DE SANEAMENTO AMBIENTAL - CETESB. IQA - Índice de qualidade das águas. São 2006.2 Disponível em: <http://www.cetesb.sp.gov.br/Agua/rios/indice_iap_iqa.asp>. Acesso em: 01 mar. 2011.

CONSELHO NACIONAL DO MEIO AMBIENTE - CONAMA. Resolução no $\mathbf{3 5 7}$ de $\mathbf{1 7}$ de março de 2005. Dispõe sobre a classificação dos corpos de água e diretrizes ambientais para o seu 
enquadramento, bem como estabelece as condições e padrões de lançamento de efluentes. Ministério do Meio Ambiente. 2005.

DAMASCENO, L.M.O. et al. Aspectos qualitativo da água do Rio Poty, na região de Teresina, PI. Revista Ciência Agronômica, v.41, n.01, p.139-148, 2010

INSTITUTO DE DESENVOLVIMENTO ECONÔMICO E MEIO AMBIENTE DO RIO GRANDE DO NORTE IDEMA, Diretoria Técnica e Administrativa. Perfil do seu Município: aspectos geoambientais e socioeconômicos. Relatório 2009.

INSTITUTO MINEIRO DE GESTÃO DAS ÁGUAS - IGAM. 2003. Disponível em: <http:// www.igam.mg.gov.br/>. Acesso em: 12 fev. 2011.

LEMOS, M.; FERREIRA NETO, M.; DIAS, N. S. Sazonalidade e variabilidade espacial da qualidade da água na Lagoa do Apodi, RN. Revista Brasileira de Engenharia Agrícola e Ambiental, v.14, n.02, p.155-164, 2010.

SILVA, A.E.P. et al. Influência da precipitação na qualidade da água do Rio Purus. Acta Amazonica, v.38, n.04, p. 733-742, 2008.

SPIRO, T. G.; STIGLIANI, W. M. Química Ambiental. 2. ed. São Paulo: Pearson Prentice Hall, 2009. $344 \mathrm{p}$.

PEREIRA, R. S. Identificação e Caracterização das Fontes de Poluição em Sistemas Hídricos. Revista Eletrônica de Recursos Hídricos, v.1 n.01, p.20-36, 2004.

PINTO FILHO, J. L. de O.; OLIVEIRA, A. M. de. Impactos socioambientais da ocupação desordenada das margens da lagoa do Apodi-RN. Revista Verde de Agroecologia e Desenvolvimento Sustentável, v.3, n.01, p.58-76, 2008.

PINTO, D. B. F. et al. Qualidade dos recursos hídricos superficiais em sub-bacias hidrográficas da região Alto Rio Grande-MG. Ciência e Agrotecnologia, v.33, n.04, p.1145-1152, 2009.

POLETO, C; CARVALHO, S.Ç. Problemas de degradação ambiental em uma microbacia hidrográfica situada no município de Ilha Solteira - SP, Brasil e sua percepção pelos proprietários rurais. Holos Environment, v.4 n.01, p.68-80, 2004.

LIMA, V. L. A. d.; CHAVES, L. H. G. Qualidade da água. In: LIMA, V. L. A. d.; BARACUHY, J. G. de V.; MEIRA FILHO, A. da S. A qualidade da água. 1. ed. Campina Grande: Gráfica Agenda, 2008. cap. 1, p. 12-23.

LOPES, F. B. et al. Mapa da qualidade das águas do rio Acaraú, pelo emprego do IQA e Geoprocessamento. Revista Ciência Agronômica, v. 39, n. 3, p. 392-402, 2008. 